\title{
Globalização: promoção de uma visão monolítica de língua e cultura?
}

\author{
Shirlei Almeida BAPTISTONE (1) \\ Universidade Federal Fluminense (UFF)
}

\section{RESUMO}

Esta resenha foi gerada a partir da conferência do Professor Rainer Enrique Hamel, na Abralin ao vivo, no dia 29/05/2020. Pretendemos problematizar o caráter homogeneizante da língua inglesa, uma vez que seu monopólio pode não somente influenciar estruturas linguísticas, mas principalmente estruturas discursivas e modelos culturais de um povo. O inglês, chamado de língua hipercentral, não tem apenas ocupado um lugar de destaque na área da Ciência, mas também "expulsado" as línguas supercentrais como se fosse um processo natural. Esse tempo de pandemia tem servido para nos mostrar que se a Ciência continuar caminhando separada da sociedade sofreremos consequências desastrosas.

OPEN ACCESS

EDITADO POR

Raquel Freitag

AVALIADO POR Ana Lúcia Fonseca

DATAS

Recebido: 05/06/2020

Aceito: $28 / 06 / 2020$ Publicado: 10/07/2020

COMO CITAR

Baptistone, S. A. (2020) Globalização: promoção de uma visão monolítica de língua e cultura? Revista da Abralin, v. 19, n. 2, p. 1-5, 2020. Observaremos alguns aspectos da prática científica pautada pela falaciosa análise bibliométrica.

\section{RÉSUMÉ}

Ce compte-rendu est celui d'une conférence du professeur Rainer Enrique Hamel à Abralin en direct le 29 mai 2020. Nous y mettons en évidence la problématique du pouvoir d'homogénéisation d'une langue, qui peut non seulement influencer une structure linguistique, mais aussi les structures discursives et les modèles culturels d'un peuple. Appelé la langue hypercentrale, l'anglais n'a pas seulement occupé une place de choix dans le domaine de la science, il a aussi "expulsé" les langues supercentrales comme s'il s'agissait d'un processus naturel. Cette période de pandémie nous a montré que si la science continue à s'écarter de la société, nous en subirons les conséquences désastreuses. Nous observerons certains aspects de la pratique scientifique guidés par une analyse bibliométrique fallacieuse. 


\section{REVISTA DA ABRALIN}

PALAVRAS-CHAVE

Ensino superior. Inglês. Globalização.

\section{MOTS-CLÉS}

Enseignement supérieur. Anglais. Mondialisation.

No dia 29 de maio de 2020, o professor Rainer Enrique Hamel, linguista da Universidad Autónoma Metropolitana do México e coordenador do Projeto "Políticas Linguísticas na América Latina", da Associação de Linguística e Filologia da América Latina (ALFAL), ministrou uma conferência online no site da Abralin, Associação Brasileira de Linguística, com o título "A globalização política, as línguas na ciência e no ensino superior: monopólio inglês ou nova diversidade na pandemia". Nesta conferência, professor Hamel apontou as falácias e as limitações do sistema bibliométrico que regulam as produções científicas. Além disso, ressaltou a defesa de espaços multilíngues na América Latina para que o monopólio do inglês não se instale silenciando nossos modelos culturais.

Entendemos a fala inicial do professor Hamel na conferência, como um ato político de resistência. Diante do alcance e da temática tratada não poderia ser diferente. O professor fez questão de começar a introdução em inglês explicando o porquê de sua preleção ser ministrada em português ou mesmo em espanhol. Para compreender a distinção terminológica que utiliza sobre a organização das línguas do mundo, Hamel se baseia no modelo gravitacional proposto por Calvet (1999, apud PEREIRA, 2006, p.92). O inglês é considerado a única língua mundializada, chamado de língua hipercentral. Em torno dela gravitam de sete a nove línguas supercentrais, a exemplo do francês, espanhol e português que, embora possuam função internacional, são mais reduzidas. Em torno dessas línguas, gravitam aproximadamente cem línguas centrais que são as línguas nacionais de países sem muita expressão internacional e aproximadamente seis mil línguas vernáculas, mas sem status principal, consideradas periféricas.

Ao chamar a atenção sobre a atual situação da Educação Superior, o professor salientou que estamos diante de um impasse vital com implicações provavelmente irreversíveis. O inglês, como a língua da ciência, tem ocupado uma posição hegemônica excluindo até mesmo os poucos espaços de prestígio reservado às línguas supercentrais (governo, administração, educação superior, comércio ou comunicação internacional). Se esse modelo monolíngue permanecer, haverá atrofia de muitas línguas na área da ciência e da tecnologia. Em outro artigo, o professor Hamel (2017, p. 244) afirmara que a convergência para uma única língua da ciência recria uma certa ilusão de unidade planetária entre os cientistas, além de ser uma grande atração. Atualmente, é notório, o aumento na quantidade de publicações científicas que faz do inglês a língua padrão. 


\section{REVISTA DA ABRALIN}

Hamel compartilhou também sua inquietação em relação ao espaço ocupado pela Bibliometria ${ }^{1}$ junto à comunidade científica. Segundo ele, tal ferramenta privilegia somente as publicações e não leva em consideração outras produções científicas reais. Nesse sentido, realizar trabalhos de campo, atuar em laboratórios e formar novos pesquisadores acabam sendo ações descartadas, como se isso não significasse produzir ciência. Essa forma de racionalidade sobre a produção de conhecimento científicos seria, para Bourdieu (1992, p. 259), uma compreensão fetichizada, limitada e naturalizada, mas que "só existe enquanto objeto simbólico dotado de valor se é conhecida e reconhecida, ou seja, socialmente instituída".

O professor ressaltou que, no ano de 2016, houve uma elevada porcentagem de publicações em inglês e uma baixa entrada em relação ao português e ao espanhol. Esses dados fazem parte de um ranking que integram a Web of Science $^{2}$, base multidisciplinar que congrega artigos de conceituadas revistas científicas publicadas no mundo, além de trabalhos de eventos. Hamel advertiu que esses dados eram falaciosos, uma vez que distorciam a realidade pela forma de selecionar, hierarquizar e excluir as publicações e as línguas. Seria coerente considerar a "relevância" e o valor científico de um artigo pelo seu impacto? Entendendo que esse termo corresponde contar o número de vezes que ele foi citado anteriormente por outros autores. O que dizer do universo de revistas que são importantes para as realidades dos países cujas citações não participam dessa realidade métrica? Seriam essas revistas menos importantes?

Convém destacar que artigos híbridos dificilmente seriam aceitos como produção científica, mesmo que a sua estrutura discursiva fosse feita nos cânones da gramática normativa do inglês, por se tratar de um discurso construído com um modelo cultural diferente. Em contrapartida, há também artigos publicados em português, espanhol e alemão cuja lógica está fundamentada em um modelo discursivo científico em inglês, americano ou anglo-saxão.

Durante seus muitos anos de pesquisa na área de Sociolinguística, Hamel percebeu que mais importante do que apenas observar as estruturas linguísticas (EL) das línguas (terminologia, gramática), é conhecer, principalmente, as suas estruturas discursivas (ED). Desse modo, o professor argumenta que cada grupo linguístico tem seus paradigmas, suas tradições, sua forma de estruturar o pensamento científico. E essa aceitação da diversidade como uma riqueza, é a concepção que Hamel desenvolve de plurilinguismo, quanto mais línguas, melhor. Esse posicionamento difere do proposto pela União Europeia. Hamel distingue o multilinguismo como o aceite da diversidade linguística, mas com orientação ideológica negativa - línguas variadas são vistas como problemas.

Hamel explica que a redução da diversidade leva a um empobrecimento da criatividade, da diversidade científica nos procedimentos específicos de temas e pesquisas. É comum haver conflito entre as línguas, uma vez que cada uma apresenta uma compreensão de mundo, modelos de conhecimentos e modelos culturais diferentes (MC). Diante disso, compreendemos porque não podemos

1 Bibliometria é uma área extensa da Ciência da Informação e abrange todos os estudos que procuram quantificar os processos da comunicação escrita, aplicando métodos numéricos específicos (FORESTI 1990, p.53).

2 Clarivate Analytics empresa privada responsável pelo acesso a base de dados Web of Science. 


\section{REVISTA DA ABRALIN}

aceitar o discurso de homogeneização do inglês como a única língua da ciência. Lembramo-nos de Hall (2019, p.11), quando ele afirma estar a sociedade projetada nessas identidades que acabam costurando ou "suturando" tanto os sujeitos quanto os mundos culturais que eles habitam, tornando-os reciprocamente mais unificados e predizíveis.

A língua inglesa não pode ser "costurada" como idioma universal sob o argumento de que é algo natural em mundo globalizado, nem tampouco precisamos abandonar o modelo plurilíngue das línguas supercentrais para ganharmos mais visibilidade nas ciências. Concordamos com Hamel que esse monopólio, essa ilusão de unificação não se refere apenas a um processo linguístico, mas principalmente a um monolinguismo ideológico dos grupos dominantes, logo de um sistema interpretativo de mundo.

Historicamente, os países da América Latina possuem um consenso que áreas como educação e saúde são direitos constitucionais, não são negócios, são bens públicos e gratuitos. Contudo, Hamel faz algumas advertências sobre um novo modelo de gestão empresarial na área da Educação Superior e na Ciência que ganha força nesses tempos de globalização. Há uma concepção que considera legítimo o indivíduo dispor de um capital para financiar seus estudos universitários, ou seja, passe a ser responsável por sua competência e conhecimentos. Isso já é uma realidade em universidades públicas da Grã-Bretanha, Estados Unidos, Chile e Colômbia. O Professor Hamel adverte que está na hora de organizarmos nossa própria história no Ensino Superior, Ciência e Pós-Graduação e uma melhor integração latino-americana. Não é mais concebível que ideologias dominantes façam com que todo um continente permaneça silenciado. É preciso haver espaços de integração da América Latina como espaços plurilíngues.

Esse tempo de pandemia tem servido para nos mostrar o quanto a crise da globalização tem implicações diretas na sociedade. Hamel acrescenta que vivemos em um sistema pervertido, complexo e desigual, o qual já se mostrou fracassado. De que adianta o cientista participar eficientemente da máxima publish or perish se a sua produtividade o distância do verdadeiro impacto social ou não provoca mudanças reais na sociedade?

Finalmente, podemos asseverar que o professor fez uma belíssima apresentação sobre a consequência de uma visão monolítica de língua e de modelo cultural. Ao mesmo tempo, ficou claro o seu lugar de fala, pois em nenhum momento defendeu um discurso de repulsa ao inglês ou a outras línguas, ressaltando apenas que elas continuassem plurais e pautadas por necessidades reais da nossa sociedade. Reafirmamos que a conferência trouxe, também, muitas reflexões que colocam em xeque índices bibliométricos que medem a eficiência acadêmica pela quantidade de produção.

Nesse sentido, mais importante do que a quantificação ou internacionalização da ciência, é o fato de ser imprescindível o conhecimento científico para atender à sociedade e ao nosso contexto latino-americano. A propósito, em todo o seu discurso, Hamel insistiu que já era tempo de pensarmos em estratégias latino-americanas, a fim de desfazermos mitos e construirmos a nossa história e o nosso modo de fazer ciência. Parabenizou, ainda, as iniciativas das universidades em editarem suas próprias revistas e as das associações em promoverem encontros como o da Abralin. Ao término da conferência, todos os participantes, enquanto sujeitos envolvidos no processo, foram convidados 


\section{REVISTA DA ABRALIN}

a se inspirar e potencializar esforços para a criação de uma nova cultura acadêmica, ao som de "Volver a Los 17", com Mercedes Sosa, Chico Buarque, Caetano Veloso, Milton Nascimento e Gal, uma canção de luta, de encorajamento e de inconformismo.

\section{REFERÊNCIAS}

A globalização política, as línguas na ciência e no ensino superior: monopólio inglês ou nova diversidade na pandemia? Conferência apresentada por Rainer Enrique Hamel [s.l., s.n], 2020.1 vídeo (1h 25min 24s). Publicado pelo canal da Associação Brasileira de Linguística. Disponível em: https://www.youtube.com/watch?v=IKuRyEFORGc Acesso em: 29 maio 2020

BOURDIEU, Pierre. As regras da arte: gênese e estrutura do campo literário. Tradução de Maria Lúcia Machado. São Paulo: Companhia das Letras. 1996.

FORESTI, Noris. Estudo da contribuição das revistas brasileiras de Biblioteconomia e Ciência da Informação enquanto fonte de referência para a pesquisa. Dissertação (Mestrado em Biblioteconomia) - Faculdade de Estudos Sociais e Aplicados, Universidade de Brasília, Brasília, DF, 1990.

HALL, Stuart. A identidade cultural na pós-modernidade. 12 ed. Rio de Janeiro: DP\&A, 2019.

HAMEL, Rainer Enrique. Enfrentando las estrategias del imperio: hacia políticas del lenguaje en las ciencias y la educación superior en América Latina. In: DINIZ, A. G.; PEREIRA, D. A.; ALVES, L. K. (Orgs.). Poéticas e políticas da linguagem em vias de descolonização. São Carlos, SP: Pedro \& João Editores, 2017b. p. 229-261.

PEREIRA, Telma Cristina de Almeida Silva. O ensino de línguas estrangeiras como um fator de inclusão social: o desafio da francofonia no Rio de Janeiro. Tese (Doutorado em Letras) - Pontifícia Universidade Católica do Rio de Janeiro, Rio de Janeiro, 2006. 